\title{
CXCR4 Tropic HIV-1 gp120 Inhibition of SDF-1 $\alpha$-Induced Chemotaxis Requires Lck and is Associated with Cofilin Phosphorylation
}

\author{
Sergey A. Trushin, Gary D. Bren and Andrew D. Badley* \\ Division of Infectious Diseases, Mayo Clinic, Rochester, MN 55905, USA
}

\begin{abstract}
Objective: HIV gp120 is a pleiotropic protein present in the plasma and tissues of HIV-infected patients, which affects a variety of homeostatic functions. In this report, we examine the mechanism of how gp120 blocks CD4 T cells from migrating towards SDF- $1 \alpha$.

Methods: In vitro treatment of primary CD4 T cells with CXCR4 tropic gp120, SDF, and measurement of chemotaxis and cell signaling.

Results: gp120 signaling through CD4 receptor and Lck are required for its ability to inhibit chemotaxis induced by SDF, as demonstrated by CD4 receptor decoys, Lck inhibitors, as well as cells deficient in Lck, in which Lck expression is restored. Blocking Lck abrogates the ability of CXCR4 tropic gp120 to antagonize SDF- $1 \alpha$-induced chemotaxis. This inhibition is associated with cofilin phosphorylation, thereby providing a potential mechanism.

Conclusion: We conclude that the ability of gp120 to inhibit SDF-1 $\alpha$-induced chemotaxis is mediated by the CD4 receptor and Lck signaling, potentially by promoting cofilin phosphorylation.
\end{abstract}

Keywords: SDF, Lck, cofilin, chemotaxis, gp120.

\section{INTRODUCTION}

During HIV infection, $\mathrm{T}$ cell homing is altered and peripheral $\mathrm{T}$ cell number is reduced while patients develop peripheral lymphadenopathy. Histology of these lymph nodes demonstrates accumulation of CD4 T cells, which is felt to favor viral dissemination and infection of CD4 T cells [1]. The signals which promote abnormal $\mathrm{T}$ cell trafficking are only partially understood. gp120 blocks CXCL8 induced chemotaxis, as well as sphingosine 1 phosphate mediated egress of $\mathrm{T}$ cells in a herbimycin A-dependent manner, suggesting that these effects are mediated by Lck [2]. Several groups have also reported that gp120 promotes non responsiveness to SDF-1 $\alpha$ (CXCL12)-induced chemotaxis in $B$ cells [3], monocytes [4] and $T$ cells [5], putatively by downregulating CXC chemokine receptor 4 (CXCR4) expression.

HIV-1 uses CD4 and one of several possible seven transmembrane $G$ protein coupled receptors for cell entry. HIV fusion with targets cells occurs through the interaction of envelope glycoprotein gp120 with the CD4 receptor that results in conformational changes allowing the binding of gp120 to CXCR4 [6-9] in the case of T tropic virus. gp120 binding leads to downregulation of CXCR4 expression [5], which has been attributed as the cause of reduced chemotaxis in response to SDF-1 $\alpha[3,5]$. CXCR4 downregulation occurs as a result of gp120 interaction with CD4 and Lck activation [10] leading to CXCR4 phosphorylation and receptor internalization [5].

*Address correspondence to this author at the Mayo Clinic College of Medicine, 200 First Street SW, Guggenheim 501, Rochester, MN 55905, USA; Tel: 507-284-2028; Fax: 507-284-3757;

E-mail: badley.andrew@mayo.edu
One early cellular response of $\mathrm{T}$ cells stimulated with SDF-1 $\alpha$ is actin cytoskeleton reorganization [11] which is regulated by cofilin. Active cofilin functions to depolymerize actin $[12,13]$ and is required for efficient chemotaxis, wherein cycles of actin polymerization and depolymerization lead to cell migration. The activity of cofilin is negatively regulated by serine/threonine phosphorylation by LIM kinase1 (LIMK1) through phosphorylation of cofilin at Ser-3 [14] which renders cofilin incapable of binding actin. In the current report, we examine the mechanism by which gp120 causes non-responsiveness to SDF- $1 \alpha$-induced chemotaxis in $T$ cells, specifically examining the role of Lck signaling, and its potential effects on cofilin.

\section{MATERIALS AND METHODS}

\section{Cell Culture and Reagents}

CD4 T cells were isolated from the blood of healthy volunteer donors by using RossetteSep CD4 enrichment cocktail in accordance with the manufacture's protocol (StemCell Technologies, Vancouver, British Columbia, Canada). The remaining cell population was repeatedly found to be $98 \% \mathrm{CD} 4 \mathrm{~T}$ cells as determined by flow cytometry. CD4 T cells were maintained in RPMI 1640 supplemented with 10\% fetal bovine serum (Invitrogen, Carlsbad, CA), $2 \mathrm{mM}$ L-glutamine, and antibiotics (penicillin $100 \mathrm{U} / \mathrm{ml}$, streptomycin $100 \mu \mathrm{g} / \mathrm{ml}$ ) at $0.5 \times 10^{6}$ cells $/ \mathrm{ml}$. CD4 $\mathrm{T}$ cells were incubated with HIV-1 X4 gp120IIIB (Immuno Diagnostics, Inc. Woburn, MA) or gp120 IIIB pretreated with soluble CD4 (1:3) (Immuno Diagnostics, Inc. Woburn, MA) at concentrations of 1 $\mu \mathrm{g} / \mathrm{ml} / 2 \times 10^{6}$ cells for indicated time at $37^{\circ} \mathrm{C}$.

SDF-1 $\alpha$ was purchased from R\&D Systems (Minneapolis, MN). Anti-Lck antibodies were purchased 
from Santa Cruz Biotechnology (Santa Cruz, CA). Antiphospho-Erk (T280/Y282), anti-Erk1/2, anti-phospho-cofilin (S3), anti-phospho-Akt (Ser473), anti-phospho-Src (Y416) and anti-cofilin antibodies were purchased from Cell Signaling Technology (Beverly, MA). Fluorescent (Oregon Green 514) phalloidin was purchased from Invitrogen (Carlsbad, CA). Anti-CXCR4-PE and anti-CD4-PE were purchased from BD Biosciences (San Jose, CA). Leupeptin, aprotinin and pepstatin A were obtained from BoehringerMannheim (Indianapolis, IN).

\section{Cell Extract Preparation, Immunoblotting}

To obtain total cellular proteins, cells were washed with cold phosphate-buffered saline (PBS), resuspended in a modified whole-cell extract buffer [15] [40 mM Tris- $\mathrm{HCl}$ $(\mathrm{pH}=8), 0.25 \mathrm{M} \mathrm{NaCl}, 1 \%$ Triton X-100, 6 mM EDTA, 6 mM EGTA, $10 \mathrm{mM}$ para-nitrophenyl phosphate, $10 \mathrm{mM} \beta$ glycerophosphate, $300 \mu \mathrm{M}$ sodium orthovanadate, $1 \mathrm{mM}$ DTT, $2 \mu \mathrm{M}$ phenylmethylsulfonyl fluoride (PMSF), aprotinin at $10 \mu \mathrm{g} / \mathrm{ml}$, leupeptin at $1 \mu \mathrm{g} / \mathrm{ml}$, pepstatin 1 $\mu \mathrm{g} / \mathrm{ml}]$ and centrifuged at $1200 \mathrm{x}$ g for $15 \mathrm{~min}$ at $4^{\circ} \mathrm{C}$. The resultant supernatant contains total cellular protein. The amount of cellular protein present in the clarified supernatant was calculated by using the Bio-Rad (Hercules, CA) protein assay.

For Western immunoblots, equal amounts of whole cell extract (WCE) were loaded and separated by SDSpolyacrylamide gel electrophoresis (PAGE) and transferred to Immobilon-P membranes (Millipore, Bedford, MA). Immunoblotting was performed with specific antibodies and visualized by using the ECL Western blotting detection kit (Amersham, Buckinghamshire, England).

Chemotaxis of primary human CD4 T cells was performed by using 24-well transmigration chamber plates $(5 \mu \mathrm{M}$ pore size, Transwell system (Costar, Cambridge, MA)). Migration buffer $(600 \mu \mathrm{l})$ containing no chemokine or $40 \mathrm{nM}$ SDF- $1 \alpha$ was added to the lower chamber and CD4 T cells were loaded onto the inserts at a density of $1 \times 106$ cells $/ 100 \mu$ l. Plates were incubated for $1 \mathrm{~h}$ at $37^{\circ} \mathrm{C}$, and the number of cells migrating into the lower chamber was determined by cell count. The percentage of cells migrating to medium without chemokine was subtracted from the percentage of cells migrating to the medium with SDF- $1 \alpha$, to calculate the percentage of specific migration.

\section{Flow Cytometry}

CD4 $\mathrm{T}$ cells were untreated or treated for indicated times with gp120 IIIB or gp120 pre-incubated with sCD4. Cells then were stimulated with SDF- $1 \alpha$ for $1 \mathrm{~min}$ at $37^{\circ} \mathrm{C}$ and then fixed and stained with fluorescent (Oregon Green 514) phalloidin according to manufacturer's instructions (Invitrogen). F-actin content was measured by using Flow analysis on FACSscan cytometer and using CellQuest software. All experiments were performed at least three times.

\section{RESULTS} gp120 Inhibits SDF-1 $\alpha$-Induced Chemotaxis But Does
Not Alter SDF-1 $\alpha$-Induced CXCR4 Signaling

First we tested whether gp120 inhibition of chemotaxis in response to SDF-1 $\alpha$ was associated with changes in CXCR4 expression or signaling. For these experiments, we used $1 \mu \mathrm{g} / \mathrm{mL}$ of gp 120 , which reflects what is likely present in the plasma of HIV-infected patients (Cummins NW, Rizza SA, Badley AD. How much gp120 is there? JID. In Press). Primary human unstimulated CD4 $\mathrm{T}$ cells were treated with or without soluble gp120 IIIB for 1 to $60 \mathrm{~min}$, and after gp120 stimulation, these cells were treated with SDF-1 $\alpha$ in a chemotaxis chamber, and SDF- $1 \alpha$-induced chemotaxis was measured. While gp120 significantly inhibits chemotaxis at all of these time points (Fig. 1A), it causes only a transient decrease in CXCR4 expression at early time points. Although receptor expression has normalized by $60 \mathrm{~min}$ (Fig. 1B), chemotaxis remains inhibited at that time. These observations confirm prior observations of gp 120 mediated downregulation of CXCR4 [5]; however, these data highlight a discordance between SDF-1 $\alpha$-induced chemotaxis being inhibited even after CXCR4 levels have normalized, suggesting that factors other than receptor downregulation alone are involved.

A

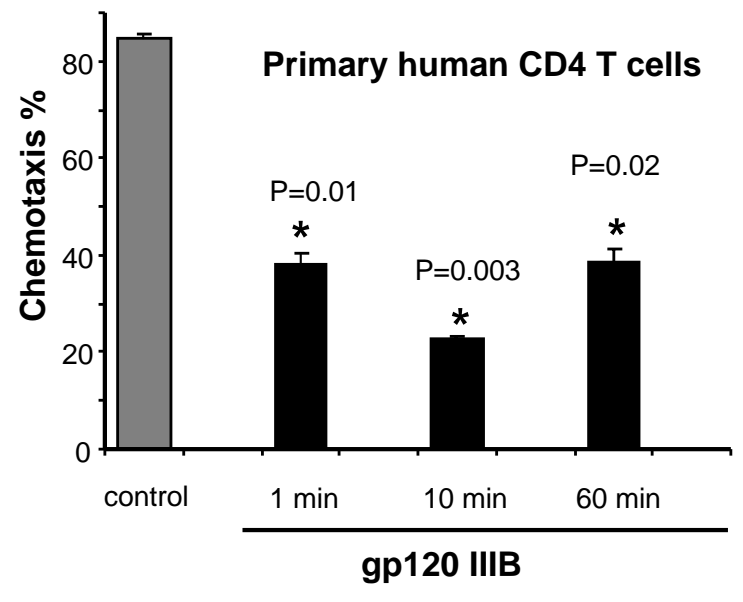

B

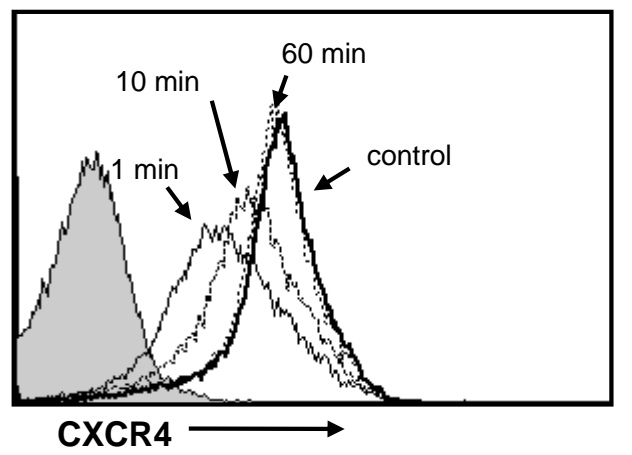

Fig. (1). gp120 inhibits SDF-1 $\alpha$-induced chemotaxis of primary human resting CD4 T cells. (A) CD4 T cells were isolated and purified (98\% pure) and pre-treated with either gp120 (IIIB) $(1 \mu \mathrm{g} / \mathrm{ml})$ or BSA $(1 \mu \mathrm{g} / \mathrm{ml})$ for indicated time to and then the percentage of CD4 $\mathrm{T}$ cells which underwent chemotaxis in response SDF-1 $\alpha$ (40nM, 1 hour) was determined. P values were determined by Student's paired t test. (B) Primary human unstimulated CD4 T cells were treated with gp120 IIIIB or BSA as described above, and expression of CXCR4 was measured by Flow Cytometry. The data is representative of three independent experiments.

While gp120 does not significantly alter CXCR4 expression at $60 \mathrm{~min}$, it may still affect signaling, therefore 
we assessed whether gp120 alters SDF-1 $\alpha$-induced activation of Erk and Akt. SDF-1 $\alpha$ stimulation of CD4 T cells resulted in (Fig. 2B) phosphorylation of Erk or Akt that was not altered by gp120. gp120 stimulation induces Lck phosphorylation regardless of whether cells are co-treated with SDF-1 $\alpha$ (Fig. 2A). Altogether, these results suggest that gp120 can inhibit chemotaxis of CD4 T cells without significantly affecting either SDF-1 $\alpha$ signaling through CXCR4, or affecting CXCR4 expression.

A

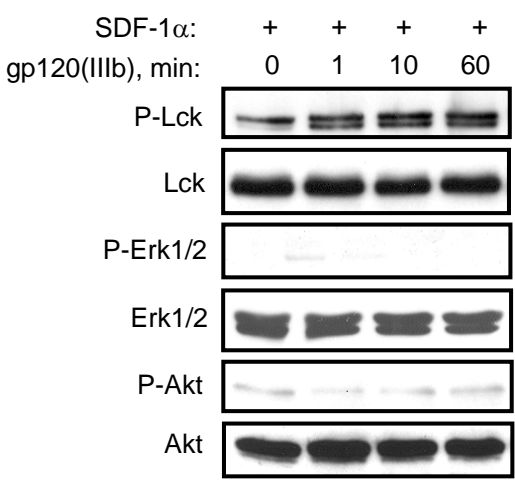

B

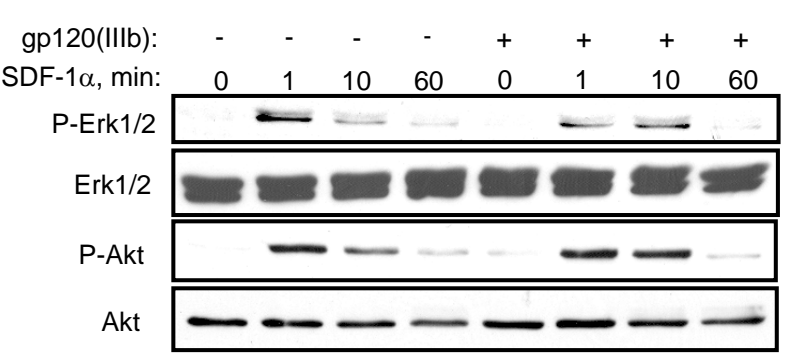

Fig. (2). gp120 does not affect G-protein dependent Erk and Akt activation by SDF-1 $\alpha$. Purified primary human CD4 T cells were treated with SDF- $1 \alpha$ and then with gp120 IIIIB $(1 \mu \mathrm{g} / \mathrm{ml})$ for the indicated times (A) or SDF-1 $\alpha(40 \mathrm{nM})$ in the presence or absence of gp120 IIIB (B). Activation of Akt, Erk and Lck were analyzed by immunoblotting with anti-phospho-S473Akt, antiphospho-Erk (T280/Y282) and anti-phospho-Y416Src. Total amount of Erk and Lck were detected with anti-Erk and anti-Lck. The data is representative of three independent experiments.

\section{gp120 Impairs SDF-1 $\alpha$-Induced F-Actin Polymerization in CD4 T Cells}

Migration of CD4 $\mathrm{T}$ cells towards SDF-1 $\alpha$ requires cytoskeleton reorganization and cyclic F-actin polymerization and depolymerization $[16,17]$. We tested if gp120 interferes with SDF-1 $\alpha$-induced F-actin polymerization which is measured as an increase in F-actin content by specific staining with fluorescent phalloidin [18] by measuring F-actin content in primary human CD4 T cells following SDF-1 $\alpha$-stimulation in the presence or absence of gp120. SDF-1 $\alpha$ treatment results in a significant increase in F-actin content (determined as a change in mean fluorescence) in CD4 T cells (Fig. 3A, B), but pre-treatment of CD4 T cells with gp120 decreases SDF- $1 \alpha$-induced Factin polymerization (Fig. $\mathbf{3 A}, \mathbf{B}$ ). To confirm the relevance of $\mathrm{F}$-actin polymerization in chemotaxis, we compared $\mathrm{F}$ - actin content in cells which had undergone chemotaxis in response to SDF-1 $1 \alpha$ with those which did not (Fig. 3C). Those cells which had not undergone chemotaxis had less Factin than those which had. Altogether these results demonstrate that gp120 impairs cytoskeleton reorganization and therefore blocks migration of CD4 T cells in response to SDF- $1 \alpha$.

A

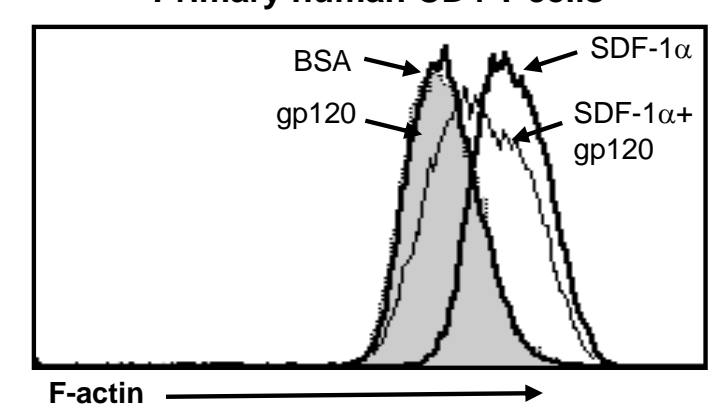

B

\section{Primary human CD4 T cells}

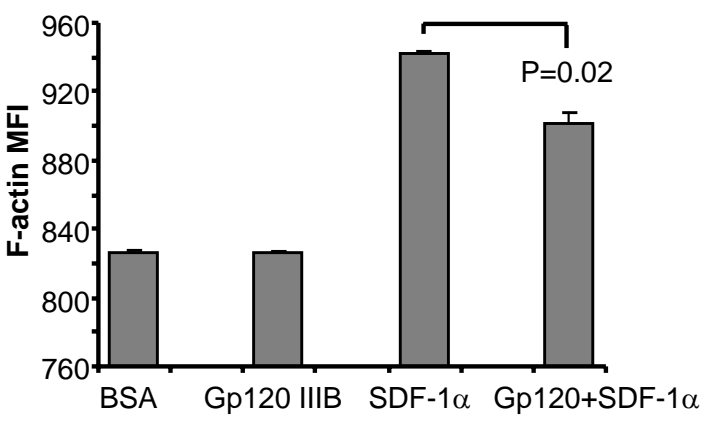

C

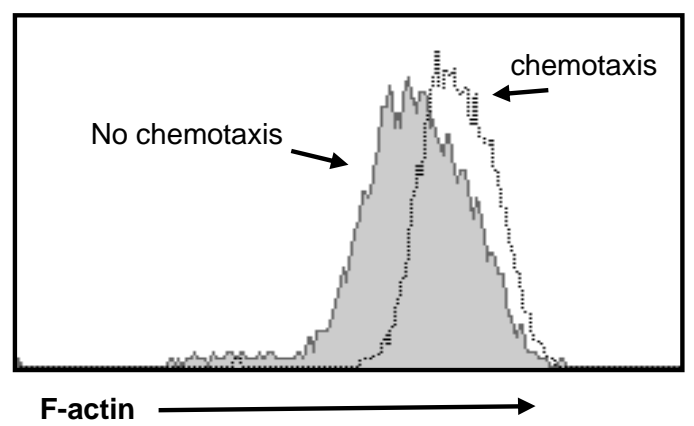

Fig. (3). gp120 inhibits SDF-1 $\alpha$-induced F-actin polymerization in CD4 T cells. (A) Purified primary human CD4 T cells were pretreated with either gp120 IIIIB $(1 \mu \mathrm{g} / \mathrm{ml})$ for $2 \mathrm{~min}$ or BSA, and then either left untreated or stimulated with SDF-1 $\alpha(40 \mathrm{nM})$ for $1 \mathrm{~min}$, and cells were analyzed for F-actin content. (B) Pooled results of three independent experiments described above (A). $\mathrm{P}$ values were determined by Student's paired $\mathrm{t}$ test. (C) Primary human unstimulated CD4 $\mathrm{T}$ cells were separated into two populations following chemotaxis in transwell chambers. Cells from upper chamber (no chemotaxis) and lower chamber (chemotaxis) were analyzed for F-actin content as described above. The data is representative of three independent experiments. 
CD4 is Required for gp120 Effect on SDF-1 $\alpha$-Induced Cofilin Phosphorylation, F-Actin - Polymerization and Chemotaxis

We next questioned whether the gp120 effect on SDF$1 \alpha$-induced chemotaxis and F-actin polymerization is mediated through CD4 or CXCR4. Primary human CD4 T cells were pre-treated with either gp120 or gp120 preincubated with soluble CD4 (sCD4); this treatment prevents gp120 binding to cell surface CD4 but still allows signaling through CXCR4 $[19,20]$. Pretreatment of gp120 with sCD4 completely reversed the inhibitory effect of gp120 on SDF$1 \alpha$-induced chemotaxis and F-actin polymerization (Fig. 4A, B).
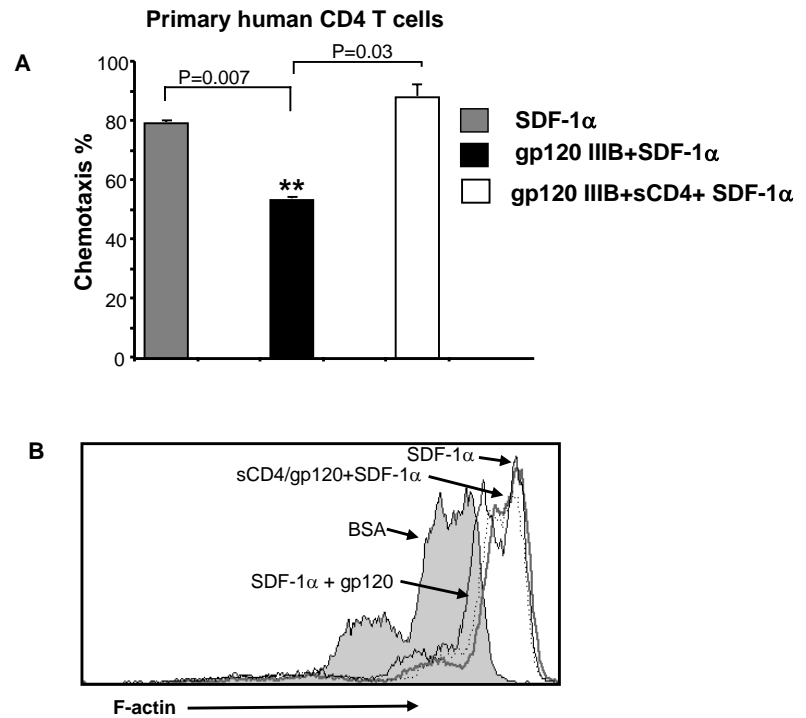

Fig. (4). CD4 is required for gp120 inhibition of SDF$1 \alpha$-induced chemotaxis. (A) Purified primary human CD4 T cells were pre-treated with either gp120 (IIIB) $(1 \mu \mathrm{g} / \mathrm{ml})$, BSA $(1 \mu \mathrm{g} / \mathrm{ml})$ or gp120 (IIIB) $(1 \mu \mathrm{g} / \mathrm{ml})$ incubated with sCD4 (1:3) and then chemotactic response of CD4 $\mathrm{T}$ cells to SDF-1 $\alpha$ (40nM, 1 hour) cells measured. $\mathrm{P}$ values were determined by Student's paired $\mathrm{t}$ test. (B) Cells were pre-treated with either gp120 (IIIB) $(1 \mu \mathrm{g} / \mathrm{ml})$, BSA $(1 \mu \mathrm{g} / \mathrm{ml})$ or gp120 (IIIB) $(1 \mu \mathrm{g} / \mathrm{ml})$ incubated with sCD4 (1:3) for 2 min and then stimulated with SDF- $1 \alpha(40 \mathrm{nM})$ for $1 \mathrm{~min}$, and Factin content was measured. The data is representative of three independent experiments.

Since cofilin is critical to actin remodeling which is necessary for chemotaxis, we next assessed whether cofilin is phosphorylated following treatment with gp120 (Fig. 5A). gp120 induces significant cofilin phosphorylation, which is followed by a decrease in total cofilin. This differs from what occurs with SDF- $1 \alpha$, where early phosphorylation is followed by a lesser decrease in total cofilin (Fig. 5B) [12]. This gp120-induced phosphorylation of cofilin is Lckdependent as demonstrated by its inhibition with the Lck inhibitor PP2 (Fig. 5C), suggesting that cofilin is directly or indirectly a downstream target of Lck.

We next studied primary CD4 $\mathrm{T}$ cell chemotaxis in response to SDF- $1 \alpha$, following gp 120 pretreatment in the presence or absence of PP2. As suggested by our cofilin phosphorylation data, SDF-1 $\alpha$-induced chemotaxis is efficiently inhibited by gp120, yet this inhibition was reversed by PP2 (Fig. 5D). Finally, we tested the effect of gp120 on SDF- $1 \alpha$-induced chemotaxis where Lck is absent. The effect of gp120 on SDF- $1 \alpha$-induced chemotaxis was studied in Lck deficient Jurkat derivative T cell lines J.CaM or J.CaM stably reconstituted with Lck (Fig. 5E). Since Lck is required for SDF-1 $\alpha$-induced chemotaxis [21], it was of no surprise that the Lck deficient J.CaM T cells underwent chemotaxis weakly in response to SDF- $1 \alpha$, however that chemotaxis which did occur was not blocked by gp120 pretreatment. In contrast after Lck expression was reconstituted both chemotaxis and its inhibition by gp120 were restored (Fig. 5E). Altogether, our results indicate that gp120 interaction with CD4 receptor induces Lck-dependent inhibition of CD4 $\mathrm{T}$ cell chemotaxis in response to SDF- $1 \alpha$ and is associated with cofilin phosphorylation.

\section{DISCUSSION}

We show that gp120 binding to the CD4 receptor inhibits the chemotactic response of CD4 T cells through an Lck dependent pathway which inhibits actin cytoskeleton reorganization and causes cofilin phosphorylation. This observation offers an explanation for prior observations that formation of the virologic synapse (VS) due to virion bound gp120 interacting with CD4 arrests migration of CD4 T cells [22], and causes a localized increase in F-actin [22]. It also supports a recently proposed model suggesting that the interaction of CD4 T cells with gp120 triggers cytoskeleton reorganization in a two step process: first actin polymerizes to form a cortical F-actin zone and second, actin depolymerization results in formation of an F-actin depleted zone underneath the gp120-rich region [23].

The fact that gp120 does not interfere with G-protein mediated SDF-1 $\alpha /$ CXCR4 signaling (Fig. 2B) indicates that both gp120 and SDF-1 $\alpha$ independently signal through CXCR4, likely because each ligand uses a distinct, but overlapping, binding sites within the extracellular domain of CXCR4 [24]. It is well established that binding of SDF- $1 \alpha$ to CXCR4 results in phosphorylation of Erk and Akt, yet it is less well understood how gp120 signals downstream of CXCR4. It has been previously reported that clustering of the CD4 and CXCR4 receptors following viral binding requires actin cytoskeletal rearrangement, which is mediated by Filamin A [25]. In this model both CD4 and CXCR4 are required for filamin A binding, which then leads to a RhoAROCK-LIMK mediated phosphorylation of cofilin which permits the F-actin reorganization required for receptor clustering. In the SDF-1 $\alpha$-induced chemotaxis model, inhibition of chemotaxis by gp 120 is completely reversed by sCD4 and by Lck inhibition and/or deficiency, demonstrating a requirement for CD4 and Lck upstream of cofilin phosphorylation. It would be of great interest to determine whether RhoA or another small GTPase is activated downstream of Lck, leading eventually to cofilin phosphorylation.

There has been recent interest in studying the impact of cofilin on HIV and vice versa. The first observation being that CXCR4 interaction with gp120 results in activation of cofilin, resulting in F-actin depolymerization, which normally functions as a restriction factor for cellular 
A

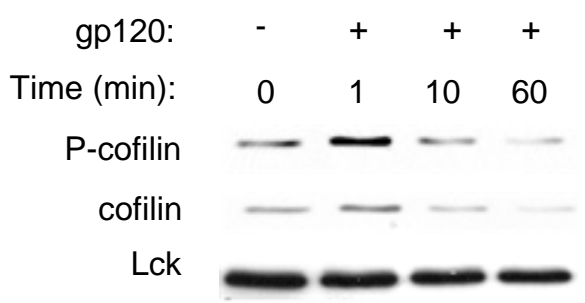

C

\begin{tabular}{|c|c|c|c|c|}
\hline gp120: & - & + & + & + \\
\hline PP2: & + & + & + & + \\
\hline Time (min): & 0 & 1 & 10 & 60 \\
\hline P-cofilin & $\cdots$ & - & - & - \\
\hline cofilin & - & - & - & - \\
\hline Lck & & & & \\
\hline
\end{tabular}

B

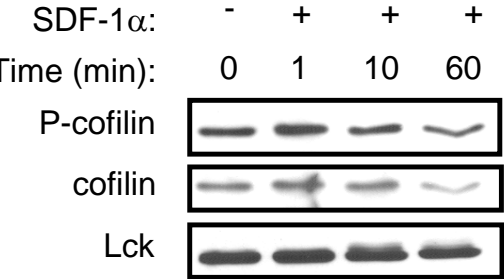

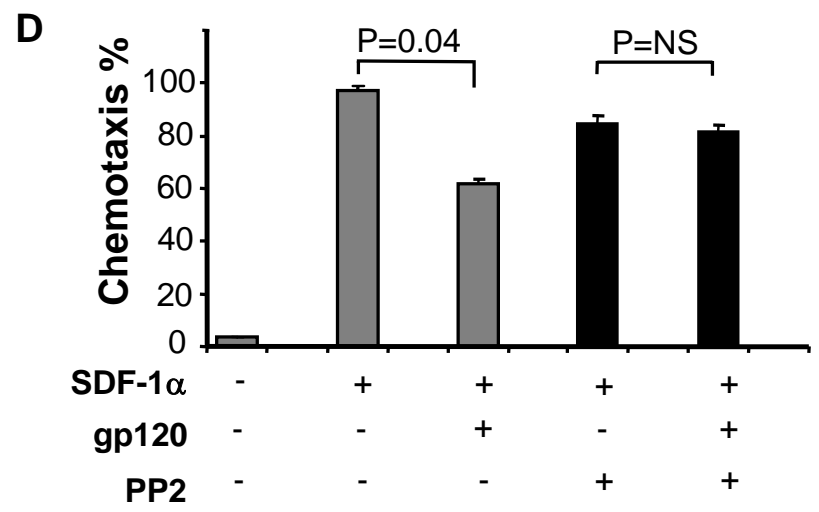

E

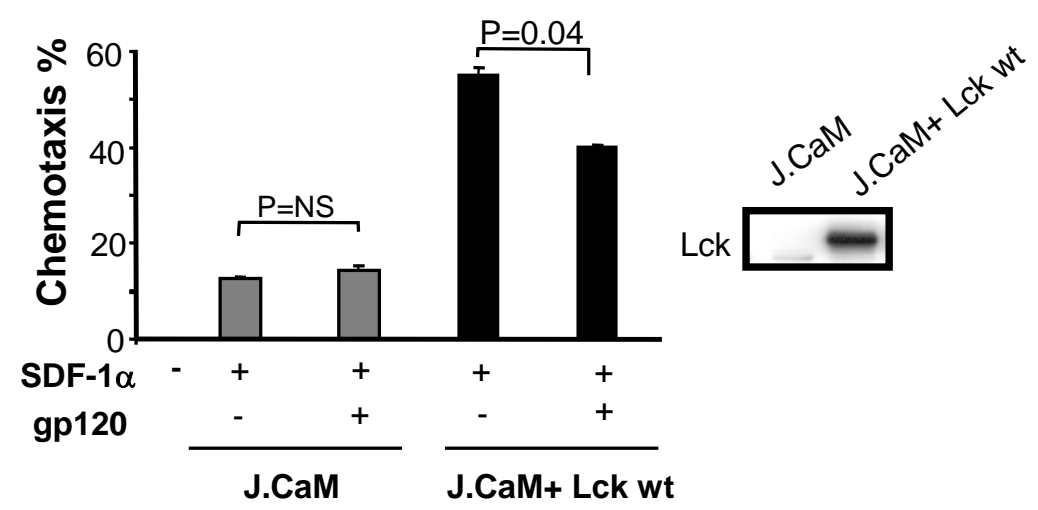

Fig. (5). Lck is required for gp120 inhibition of SDF-1 $\alpha$-induced chemotaxis. (A) Purified primary human CD4 T cells were treated with either gp120 (IIIB) $(1 \mu \mathrm{g} / \mathrm{ml})$ or (B) SDF-1 $\alpha$ and analyzed for cofilin phosphorylation over time by immunoblotting with anti-phosphoS3cofilin. (C) Primary human CD4 T cells were pre-treated with Lck inhibitor PP2 $(2 \mu \mathrm{M})$ for two hours and then treated with gp120 (IIIB) $(1 \mu \mathrm{g} / \mathrm{ml})$ and analyzed for cofilin phosphorylation over time. (D) Cells were pre-treated with either gp120 (IIIB) or BSA (1 $\mu \mathrm{g} / \mathrm{ml})$ for $2 \mathrm{~min}$ and then chemotactic response to SDF-1 $\alpha(40 \mathrm{nM})$ in the presence or absence of the Lck inhibitor PP2 was measured in transwell chemotaxis chambers. P values were determined by Student's paired t test. (E) J.CaM T cells and J.CaM T cells stably expressing wild-type Lck were pre-treated with either gp120 (IIIB) $(1 \mu \mathrm{g} / \mathrm{ml})$ or BSA $(1 \mu \mathrm{g} / \mathrm{ml})$ for $2 \mathrm{~min}$ and then chemotactic response to SDF-1 $\alpha$ (40nM) was measured in transwell chemotaxis chambers for 1 hour. Expression of Lck was confirmed by immunoblotting. P values were determined by Student's paired t test.

infection in resting CD4 $\mathrm{T}$ cells [26]. Thereafter conflicting results have been observed in patient samples, where treatment of CD4 $\mathrm{T}$ cells with gp120 results in cofilin dephosphorylation after 24 hours, but cofilin phosphorylation after 15 minutes of treatment with whole virus [27]. More recently Nef has been observed to cause hyperphosphorylation of cofilin, resulting in an impaired chemotactic response of cells to a variety of chemotactic stimuli. This effect was due to the known interaction of $\mathrm{Nef}$ with Pak2, which the authors suggest directly phosphorylates cofilin [28]. Results contained in the current report are consistent with this existing information, and further increase the body of knowledge concerning the regulation of cofilin in HIV infection. While gp120 signaling through CXCR4 causes cofilin dephosphorylation, facilitating infection, gp120 interaction with CD4 induces a hyperphosphorylation of cofilin as was seen within 1-15 minutes but not following overnight incubation with whole virus $[25,27]$. In a manner similar to that employed by Nef, the gp120:CD4 hyperphosphorylation of cofilin, results in impaired cellular migration. While we have shown this to be CD4 receptor and Lck dependent, cofilin is unlikely to be a direct target of Lck, and therefore future work will be required to elucidate the down stream kinase responsible for cofilin 
phosphorylation following gp120 triggering of the CD4 receptor.

\section{ACKNOWLEDGEMENTS}

Principal Contributions: Sergey Trushin, Gary Bren, and Andrew Badley designed the research; Sergey Trushin and Gary Bren performed the research; Andrew Badley analyzed the data; and Sergey Trushin and Andrew Badley wrote the paper.

Conflicting Interests: There are no conflicting or financial interests by the authors.

Grant Support: Dr. Andrew Badley's work is supported by grant R01 AI40384 from the National Institutes of Health.

\section{REFERENCES}

[1] Pantaleo G, Graziosi C, Demarest JF, et al. HIV infection is active and progressive in lymphoid tissue during the clinically latent stage of disease. Nature 1993; 362: 355-8.

[2] Green DS, Center DM, Cruikshank WW. Human immunodeficiency virus type 1 gp120 reprogramming of CD4+ Tcell migration provides a mechanism for lymphadenopathy. J Virol 2009; 83: 5765-72.

[3] Badr G, Borhis G, Treton D, Moog C, Garraud O, Richard Y. HIV type 1 glycoprotein 120 inhibits human B cell chemotaxis to CXC chemokine ligand (CXCL) 12, CC chemokine ligand (CCL)20, and CCL21. J Immunol 2005; 175: 302-10.

[4] Deng X, Ueda H, Su SB, et al. A synthetic peptide derived from human immunodeficiency virus type 1 gp120 downregulates the expression and function of chemokine receptors CCR5 and CXCR4 in monocytes by activating the 7-transmembrane G-protein-coupled receptor FPRL1/LXA4R. Blood 1999; 94: 1165-73.

[5] $\mathrm{Su} \mathrm{SB}$, Gong W, Grimm M, et al. Inhibition of tyrosine kinase activation blocks the down-regulation of CXC chemokine receptor 4 by HIV-1 gp120 in CD4+ T cells. J Immunol 1999; 162: 712832 .

[6] Deng HK, Unutmaz D, KewalRamani VN, Littman DR. Expression cloning of new receptors used by simian and human immunodeficiency viruses. Nature 1997; 388: 296-300.

[7] Feng Y, Broder CC, Kennedy PE, Berger EA. HIV-1 entry cofactor: functional cDNA cloning of a seven-transmembrane, $G$ protein-coupled receptor. Science 1996; 272: 872-7.

[8] Trkola A, Dragic T, Arthos J, et al. CD4-dependent, antibodysensitive interactions between HIV-1 and its co-receptor CCR-5. Nature 1996; 384: 184-7.

[9] Wu L, Gerard NP, Wyatt R, et al. CD4-induced interaction of primary HIV-1 gp120 glycoproteins with the chemokine receptor CCR-5. Nature 1996; 384: 179-83.

[10] Goldman F, Jensen WA, Johnson GL, Heasley L, Cambier JC. gp120 ligation of CD4 induces p56lck activation and TCR desensitization independent of TCR tyrosine phosphorylation. J Immunol 1994; 153: 2905-17.

[11] Pantaloni D, Le Clainche C, Carlier MF. Mechanism of actin-based motility. Science 2001; 292: 1502-6.
[12] Milligan L, Forne T, Antoine E, et al. Turnover of primary transcripts is a major step in the regulation of mouse H19 gene expression. EMBO Rep 2002; 3: 774-9.

[13] Moon A, Drubin DG. The ADF/cofilin proteins: stimulusresponsive modulators of actin dynamics. Mol Biol Cell 1995; 6: 1423-31.

[14] Arber S, Barbayannis FA, Hanser H, et al. Regulation of actin dynamics through phosphorylation of cofilin by LIM-kinase. Nature 1998; 393: 805-9.

[15] Trushin SA, Bren GD, Asin S, Pennington KN, Paya CV, Badley AD. Human immunodeficiency virus reactivation by phorbol esters or T-cell receptor ligation requires both PKCalpha and PKCtheta. J Virol 2005; 79: 9821-30.

[16] Fukui Y, Hashimoto O, Sanui T, et al. Haematopoietic cell-specific $\mathrm{CDM}$ family protein DOCK2 is essential for lymphocyte migration. Nature 2001; 412: 826-31.

[17] Vicente-Manzanares M, Cruz-Adalia A, Martin-Cofreces NB, et al. Control of lymphocyte shape and the chemotactic response by the GTP exchange factor Vav. Blood 2005; 105: 3026-34.

[18] Vicente-Manzanares M, Viton M, Sanchez-Madrid F Measurement of the levels of polymerized actin (F-actin) in chemokine-stimulated lymphocytes and GFP-coupled cDNA transfected lymphoid cells by flow cytometry. Methods Mol Biol 2004; 239: 53-68.

[19] Salzwedel K, Smith ED, Dey B, Berger EA. Sequential CD4coreceptor interactions in human immunodeficiency virus type 1 Env function: soluble CD4 activates Env for coreceptor-dependent fusion and reveals blocking activities of antibodies against cryptic conserved epitopes on gp120. J Virol 2000; 74: 326-33.

[20] Sullivan N, Sun Y, Sattentau Q, et al. CD4-Induced conformational changes in the human immunodeficiency virus type 1 gp120 glycoprotein: consequences for virus entry and neutralization. J Virol 1998; 72: 4694-703.

[21] Inngjerdingen M, Torgersen KM, Maghazachi AA. Lck is required for stromal cell-derived factor 1 alpha (CXCL12)-induced lymphoid cell chemotaxis. Blood 2002; 99: 4318-25.

[22] Vasiliver-Shamis G, Tuen M, Wu TW, et al. Human immunodeficiency virus type 1 envelope gp120 induces a stop signal and virological synapse formation in noninfected CD4+ T cells. J Virol 2008; 82: 9445-57.

[23] Liu Y, Belkina NV, Shaw S. HIV infection of T cells: actin-in and actin-out. Sci Signal 2009; 2: pe23.

[24] Tian S, Choi WT, Liu D, et al. Distinct functional sites for human immunodeficiency virus type 1 and stromal cell-derived factor 1alpha on CXCR4 transmembrane helical domains. J Virol 2005; 79: $12667-73$.

[25] Jimenez-Baranda S, Gomez-Mouton C, Rojas A, et al. Filamin-A regulates actin-dependent clustering of HIV receptors. Nat Cell Biol 2007; 9: 838-46.

[26] Yoder A, Yu D, Dong L, et al. HIV envelope-CXCR4 signaling activates cofilin to overcome cortical actin restriction in resting CD4 T cells. Cell 2008; 134: 782-92.

[27] $\mathrm{Wu} \mathrm{Y}$, Yoder A, Yu D, et al. Cofilin activation in peripheral CD4 T cells of HIV-1 infected patients: a pilot study. Retrovirology 2008; 5: 95 .

[28] Stolp B, Reichman-Fried M, Abraham L, et al. HIV-1 Nef interferes with host cell motility by deregulation of Cofilin. Cell Host Microbe 2009; 6: 174-86. 